\title{
PELUANG MENGEMBANGKAN KEBUDAYAAN DESA BERBASIS POTENSI DESA
}

\author{
Rizki Fatullah \\ Universitas Banten Jaya, Jl Ciwaru Raya 2 No 73 Kota Serang Banten, Indonesia \\ Email: rizkifath@unbaja.ac.id
}

\begin{abstract}
Student Work Program Activities Program Has Aims To increase the Potential of Cultural Skills in the Village Community Especially young people. The partners of the activity are non-productive youth in the angsana village, Kec. Mancak. The problem faced is the lack of potential of the agricultural sector so that the culture that will be lifted into superiority angsana village. The method of implementing this service is Survey Through observation, interview and problem analysis. The results of this program are increasing community knowledge and skills regarding the importance of pencak silat culture as a village cultural potential, and increasing public awareness of the importance of Pencak Silat culture.
\end{abstract}

Keywords: Village Development; Pencak Silat culture; Village Potential.

\begin{abstract}
ABSTRAK
Program Kegiatan Kuliah Kerja Mahasiswa Memiliki Tujuan Untuk meningkatkan Potensi Keterampilan Kebudayaan Masyarakat Desa Khususnya para pemuda. Mitra dari kegiatan adalah pemuda non produktif di desa angsana, Kec. Mancak. Permasalahan yang dihadapi adalah kurangnya potensi dari sektor pertanian sehingga kebudayaan yang akan di angkat menjadi keunggulan desa angsana. Metode pelaksanaan pengabdian ini yaitu Survai Melalui pengamatan, wawancara serta analisis permasalahan. Hasil dari program ini adalah bertambahnya pengetahuan dan keterampilan masyarakat mengenai pentingnya kebudayaan pencak silat sebagai potensi kebudayaan desa, serta meningkatkan kesadaran masyarakat penting nya budaya Pencak Silat.
\end{abstract}

Kata Kunci: Pengembangan Desa; Pencak Silat; Potensi Desa.

\section{PENDAHULUAN}

Mayoritas penduduk Kelurahan Angsana mempunyai mata pencaharian Petani, Pedagang dan Pegawai Swasta. Dalam hal pendidikan masih banyak kurangnya tenaga kerja guru sehingga mengakibatkan kurangnya penyampaian ilmu pengetahuan di dalam bidang pendidikan dan teknologi, sehingga masih banyak anak-anak berkurangnya pengetahuan dan teknologi. Faktorfaktor yang menyebabkan hal tersebut karena masyarakat tidak tahu pentingnya pendidikan bagi kelangsungan hidup, banyak dari mereka (masyarakat perdesaan) yang berfikir "untuk apa sekolah? asalkan sudah mencari uang tidak perlu sekolah". Serta Letak geografis yang menyulitkan untuk mengakses masyarakat menuju sekolah mulai dari jalanan yang rusak, tidak adanya alat transportasi seperti kendaraan umum. Dalam hal agama di Desa Angsana ini cukup kental dalam ibadah yang sangat religious baik tokoh masyarakat maupun pemuda dan pemudinya. Masyarakat masih banyak 
menjunjung tinggi tradisi nilai budaya secara turun menurun seperti mengikuti upacara adat yang dilakukan di desa tersebut. Dan juga terdapat sebuah padepokan APTBI (Asosiasi Pencak silat Tradisional Banten Indonesia) yang terletak di kp. Cibangka RT 05 Desa Angsana Kecamatan Mancak. Abah Tuki merupakan Pelatih Sekaligus pendiri padepokan tersebut, Padepokan ini merupakan padepokan pertama dan satu-satu nya yang di dirikan di Desa Angsana Kec. Mancak. para murid-murid yang berlatih silat berasal dari berbagai Desa di Kec. Mancak dan juga dari berbagai daerah di Luar Banten.

Setiap Minggunya di padepokan selalu melakukan latihan rutin dan juga pentas di $\mathrm{kp}$. Cibangka, agar tradisi dan kebudayaan pencak silat ini terus berlangsung dan berkembang, Abah tuki selalu melakukan pelatihan dan pembinaan maupun pentas di berbagai desa di kecamaan mancak. Padepokan APTBI (Asosiasi Pencak silat Tradisional Banten Indonesia) yang terletak di kp. Cibangka RT 05 Desa Angsana Kec. Mancak, bisa di bilang merupakan pusat dari seni beladiri yang terletak di kecamatan Mancak.

\section{Profile Desa Agsana}

Desa Angsana berdiri tahun 1942. Nama Angsana berasal dari nama sebuah pohon keramat yang berada di lingkungan desa yang pada jaman dahulu sulit sekali untuk ditebang sehingga para sesepuh berinisiatif mengambil nama desa ini dari pohon tersebut yaitu pohon Angsana, maka terbentuklah sebuah nama "DESA ANGSANA".

Letak Kelurahan Angsana Kecamatan Mancak Kabupaten Serang yaitu terletak $1 \mathrm{Km}$ jarak ke ibu kota Kecamatan terdekat, 10 menit lama jarak tempuh ke ibu kota Kecamatan, 30 km jarak ke ibu kota Kabupaten, 45 menit lama jarak tempuh ke ibu kota Kabupaten adapun batas Kelurahan Angsana Kecamatan Mancak Kabupaten Serang adalah sebagai berikut :

- Sebelah Utara : Desa Balekambang

- Sebelah selatan : Kec. Gunung Sari

- Sebelah Barat : Desa Ciwarna

- Sebelah Timur : Desa Talaga

Luas Desa Angsana Kecamatan Mancak Kabupaten Serang adalah 1036 Ha. Yang terdiri dari berbagai jenis lahan yang meliputi 132,5 Ha lahan pertanian/perkebunan, 736 Ha lahan pemukiman, 0 Ha lahan kehutanan, 100 Ha lahan ladang/tegalan, 40 Ha lahan rawa-rawa, 3 Ha lahan perkantoran, $3 \mathrm{Ha}$ lahan sekolah, $20 \mathrm{Ha}$ lahan jalan, 1,5 Ha lahan Sepak Bola. (Sumber: data 
kelurahan Angsana). Dibawah ini merupakan tabel Komposisi Penduduk Menurut Jumlah Jiwa dan Tingkat Pendidikan.

Tabel 1. Komposisi Penduduk Angsana

\begin{tabular}{|c|l|c|}
\hline No & \multicolumn{1}{|c|}{ Komposisi Penduduk } & Jumlah \\
\hline 1 & Jumlah Penduduk & 2402 \\
& a. Laki - laki & 2166 \\
\hline 2 & b. Perempuan & 976 \\
\hline 3 & Jumlah KK & \\
& Pendidikan & 247 \\
& a. Jumlah penduduk SD/MI & 58 \\
& b. Jumlah penduduk SLTP/MTS & 60 \\
& c. Jumlah penduduk SLTA/MA & 25 \\
& d. Jumlah penduduk S1/Diploma & 32 \\
& e. Putus Sekolah & 12 \\
\hline
\end{tabular}

(Sumber: Kelurahan Angsana)

\section{METODE}

Dalam Penelitian ini menggunakan metode deskriptif analitis dengan studi pengembangan untuk mengetahui tumbuh kembangnya Potensi Budaya desa.penelitian deskriptif berusaha mendeskriptifkan dan menginterpretasikan seatu hal yakni proses tentang Kebudayaan desa,berbagai pendapat yang berkembang tentang desa maupun akibat yang terjadi ketika desa berlangsung. Fokus utama yang kami lakukan pada desa Angsana kecamatan Mancak kabupaten serang yakni melihat dari pelaku Kebudayaan yang selama ini mereka haya berlatih dipadepokan dan belum mampu go publik. Analisa data pada penelitian ini yakni dari data kualitatif yang di interpretasikan kedalam pembahasan penulis dengan menhubungkan hasil temuan dilapangan dengan teori baku yang sudah ada dan sering dipakai peneliti sebelumnya.

\section{HASIL DAN PEMBAHASAN}

Kondisi Desa Angsana saat ini sedang dalam tahap pengembangan potensi desa dari hasil SDA dan kearifan lokal yang dimilikinya sehingga para remaja pra sekolah sudah mulai mengenal bangku sekolah yang lebih tinggi yakni banyak yang sedang kuliah baik diwilayah Provinsi Banten maupun di luar Kabupaten serang,sehingga nantinya bisa diharapkan generasi penerusnya bisa 
menelurkan ilmunya ketika mereka sudah lulus kuliah sehingga bisa membangun desa dengan ilmu terapan yang ada di desa. Dibawah ini merupakan tabel komposisi penduduk menurut Mata Pencaharian.

Tabel 2. Jenis Mata Pencaharian

\begin{tabular}{|c|l|c|}
\hline No & Jenis Mata Pencaharian & Jumlah \\
\hline 1 & Petani & 500 \\
\hline 2 & Pedagang & 100 \\
\hline 3 & PNS & 13 \\
\hline 4 & Tukang & 8 \\
\hline 5 & Guru & 28 \\
\hline 6 & Bidan/Perawat & 0 \\
\hline 7 & TNI/Polri & 2 \\
\hline 8 & Pensiunan & 5 \\
\hline 9 & Sopir/Angkutan & 24 \\
\hline 10 & Buruh & 31 \\
\hline 11 & Jasa Persewaan & 0 \\
\hline 12 & Pegawai Swasta & 385 \\
\hline
\end{tabular}

(Sumber: Kelurahan Angsana)

\section{KESIMPULAN}

Secara umum dapat disimpulkan bahwa Desa Angsana memiliki potensi wisata \& Kebudayaan yang merupakan karakteristik dan kebanggaan warga Desa Angsana serta dapat dikembangkan guna kesejahteraan masyarakat desa. Disamping potensi dimilikinya, Desa Angsana memiliki permasalahan-permasalahan yang meliputi kehidupan masyarakat, akan tetapi permasalahan yang timbul ini tidak menghambat aktivitas masyarakat desa. Masyarakat desa termotivasi untuk meminimalisasi permasalahan guna memperbaiki kesejahteraan hidup masyarakat.

\section{DAFTAR PUSTAKA}

KKM Kelompok 3 Desa Angsana Kecamatan Mancak Kab Serang Banten.

Lesmana, F. (2013). Silat Kumango-Belubus. Yogyakarta: Nusa Media.

Pamungkas, J. (2012) Panduan Lengkap Beladiri dengan Tenaga Dalam, Bandung: Araska. 